\title{
Directing the Solid-State Organization of Racemates via Structural Mutation and Solution-State Assembly Processes
}

\author{
Chidambar Kulkarni, ${ }^{\dagger}$ José Augusto Berrocal, ${ }^{\dagger}{ }^{\dagger}$ Martin Lutz, ${ }^{\dagger}$ Anja R. A. Palmans, ${ }^{*}{ }^{\dagger}$ (৫) \\ and E. W. Meijer*to

\begin{abstract}
${ }^{\dagger}$ Laboratory of Macromolecular and Organic Chemistry and Institute for Complex Molecular Systems (ICMS), Eindhoven University of Technology, P.O. Box 513, 5600 MB Eindhoven, The Netherlands

${ }^{\ddagger}$ Crystal and Structural Chemistry, Bijvoet Center for Biomolecular Research, Utrecht University, $3584 \mathrm{CH}$ Utrecht, The
\end{abstract} \\ Netherlands
}

\section{Supporting Information}

ABSTRACT: Chirality plays a central role in biomolecular recognition and pharmacological activity of drugs and can even lead to new functions such as spin filters. Although there have been significant advances in understanding and controlling the helical organization of enantiopure synthetic molecular systems, rationally dictating the assembly of mixtures of enantiomer (including racemates) is nontrivial. Here we demonstrate that a subtle change in molecular structure coupled with the understanding of assembly processes of enantiomers and racemates, in both dilute solution and concentrated gels, acts as a stepping stone to

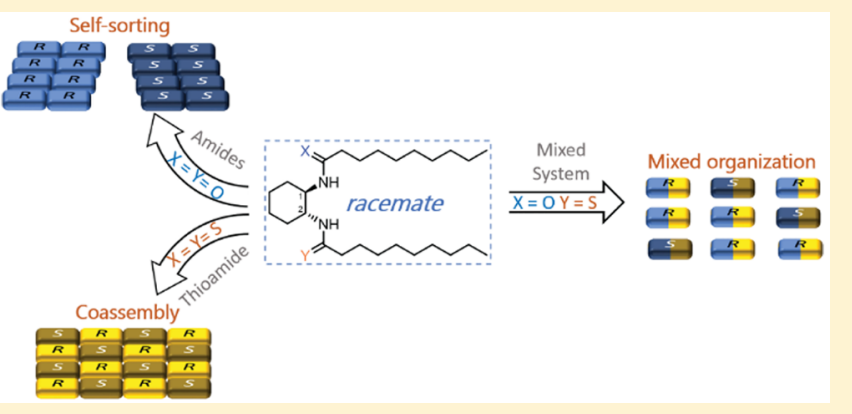
rationally control the organization in the solid-state. We have studied trans-1,2-disubstituted cyclohexanes as model systems with carboxamide, thioamide, and their combination as functional groups. On comparing the gelation propensity of individual enantiomers and racemates, we find that racemates of carboxamide, thioamide, and their combination adopt self-sorting, coassembly, and mixed organization, respectively. Remarkably, these modes of assembly of racemates were also retained in solid-state. These results point out that studying the solution-phase assembly is a key link for connecting molecular structure with the assembly in the solid-state, even for racemates.

\section{INTRODUCTION}

Pasteur's seminal work on the physical separation of tartaric acid enantiomers in 1848 has heralded studies to understand and apply the distinct properties of enantiomers and their mixtures in a range of systems from small molecules to polymers. ${ }^{1}$ An equimolar mixture of enantiomers is called a "racemate", and it can exist as one of the following: (i) a physical mixture of two noninteracting enantiomers (conglomerate), (ii) a mixture of enantiomers interacting at a molecular level (true racemate), or (iii) a disordered mixture of enantiomers (solid-solution)., ${ }^{2,3}$ Conglomerates are ideally suited for enriching one of the enantiomers through deracemization to obtain optically active compounds for use in pharmaceutical drugs. ${ }^{4-7}$ On the other hand, a true racemate or stereocomplex exhibits higher melting temperature $\left(T_{\mathrm{m}}\right)$ and improved material properties for conventional polymers such as poly(lactide)s. ${ }^{8}$ A similar organization for an organic semiconductor such as 1-aza[6]helicene leads to over 80 -fold enhancement in the electronic properties of a racemate in thin films compared to its enantiomers. ${ }^{9}$ Finally, solid-solutions ${ }^{10,11}$ are known to exhibit unique arrangements resembling plastic crystals (rotatory phase) in the solid-state, and such packings are both fundamentally intriguing ${ }^{12}$ and technologically relevant for applications such as proton conduction channels in fuel cells. ${ }^{13}$ Although controlling the organization of enantiomers in a racemate is paramount and has been extensively studied, ${ }^{14-20}$ it is highly dependent on the system and still poorly understood.

Among a plethora of synthetic systems, trans-1,2-disubstituted cyclohexane derivatives are an important class of chiral compounds with utility in asymmetric epoxidation cataly$\operatorname{sis}^{21,22}$ functional materials, ${ }^{23-25}$ and organogels. ${ }^{26}$ At a mesoscopic level, it has been demonstrated that trans-1,2bis(amido)cyclohexanes with linear alkyl chain substituents on the amides undergo head-to-tail intermolecular hydrogen bonding, leading to a long, one-dimensional aggregate which can further entangle to gelate organic solvents at high solute concentrations. ${ }^{26,27}$ Both the enantiomeric purity (enantiopure vs racemic) of the sample $e^{26,28}$ and the nature of substituents on amide (alkyl chain or perfluoroalkyl chains) ${ }^{29,30}$ significantly affect the gelation behavior. On the other hand, at dilute concentration in apolar solvents, amide and urea derivatives of trans-1,2-cyclohexane enantiomers mainly exist as self-sorted assemblies, ${ }^{31,32}$ and their coassembly has been shown to be triggered by specific charge-transfer ${ }^{33}$ or energy-transfer ${ }^{34,35}$

Received: January 14, 2019

Published: March 28, 2019 
interactions. Although there are various examples of selfsorting or coassembly in solution-phase supramolecular chemistry using elegant molecular designs, ${ }^{31,36-39}$ engineering the organization of enantiomers in the solid-state is still a challenging task.

One of the ways to profoundly influence the organization and properties of a system is by subtle structural changes. ${ }^{40} \mathrm{~A}$ typical example of such a change is the structural isomerism (ovs $p$-substitution) coupled with polymorphism to dictate the conglomerate or true racemate organization as observed in mandelic acids. ${ }^{41,42}$ On the other hand, changing an urea group to a thiourea group has resulted in highly efficient organocatalysts in solution ${ }^{43}$ and self-healing polymeric materials in the solid-state. ${ }^{44}$ Moreover, thioamides exhibit strong intermolecular hydrogen bonding, ${ }^{45,46}$ increased proteolytic stability, ${ }^{47}$ and an opportunity to switch the conformation from trans- to cis-thioamide with UV light. ${ }^{48}$ However, the effect of the substitution of a carboxamide by a thioamide moiety has been rather underexplored to dictate solid-state organization. Here we harness this subtle structural effect of substitution of a carboxamide by thioamide in the trans-1,2-disubstituted cyclohexane systems and investigate the effect of such mutation at the molecular, mesoscopic (gels), and solid-state level. Remarkably, we have observed conglomerate, true racemate, and solid-solution in a single molecular system in the solid-state based on changing one or two of the carboxamides into thioamides.

\section{RESULTS AND DISCUSSION}

The system we have studied here is based on trans-1,2disubstituted cyclohexane derivatives with $n$-nonane side chains (Figure 1a). The carboxamide derivatives ((1S,2S)-1, $(1 R, 2 R)-1$, and (rac)-1) were synthesized by coupling the corresponding commercially available diamines with decanoyl chloride. The carboxamides were converted into their corresponding thioamides (Figure 1a) using phosphorus pentasulfide as the thionating agent under reflux conditions in toluene. The detailed synthetic procedures and characterization are provided in the Supporting Information (Scheme S1). The purified carboxamide derivatives (1) were all solid powders at room temperature. However, the enantiopure thioamides $((1 S, 2 S)-2$ and $(1 R, 2 R)-2)$ were low melting solids, which became solids only after prolonged standing at room temperature. This already suggested that carboxamides (1) and thioamides (2) show different properties in the solidstate.

Assembly Characteristics of Carboxamides and Thioamides from Dilute Solutions to Gels. We first investigated the assembly characteristics of both $\mathbf{1}$ and $\mathbf{2}$ in dilute apolar solvents, as both carboxamide ${ }^{49}$ and thioamide ${ }^{45}$ motifs are known to assemble via intermolecular hydrogen bonding, leading to elongated one-dimensional (1-D) structures in solution. Circular dichroism (CD) spectrum of $(1 R, 2 R)-1$ in methylcyclohexane $(\mathrm{MCH})(c=435 \mu \mathrm{M})$ exhibit a negative Cotton effect at $220 \mathrm{~nm}$ (Figure $1 \mathrm{~b}$ ). Variabletemperature (VT) CD measurements show that the molar circular dichroism $(\Delta \varepsilon)$ decreases at higher temperatures but does not completely vanish at $95{ }^{\circ} \mathrm{C}$, indicative of an asymmetrically perturbed chromophore. The temperature dependence of the molar circular dichroism suggests that carboxamide groups engage in intermolecular interactions. Atomic force microscopy of a $(1 R, 2 R)-1$ film on mica obtained by drop-casting a solution of $\mathrm{MCH}(c=383 \mu \mathrm{M})$ shows a
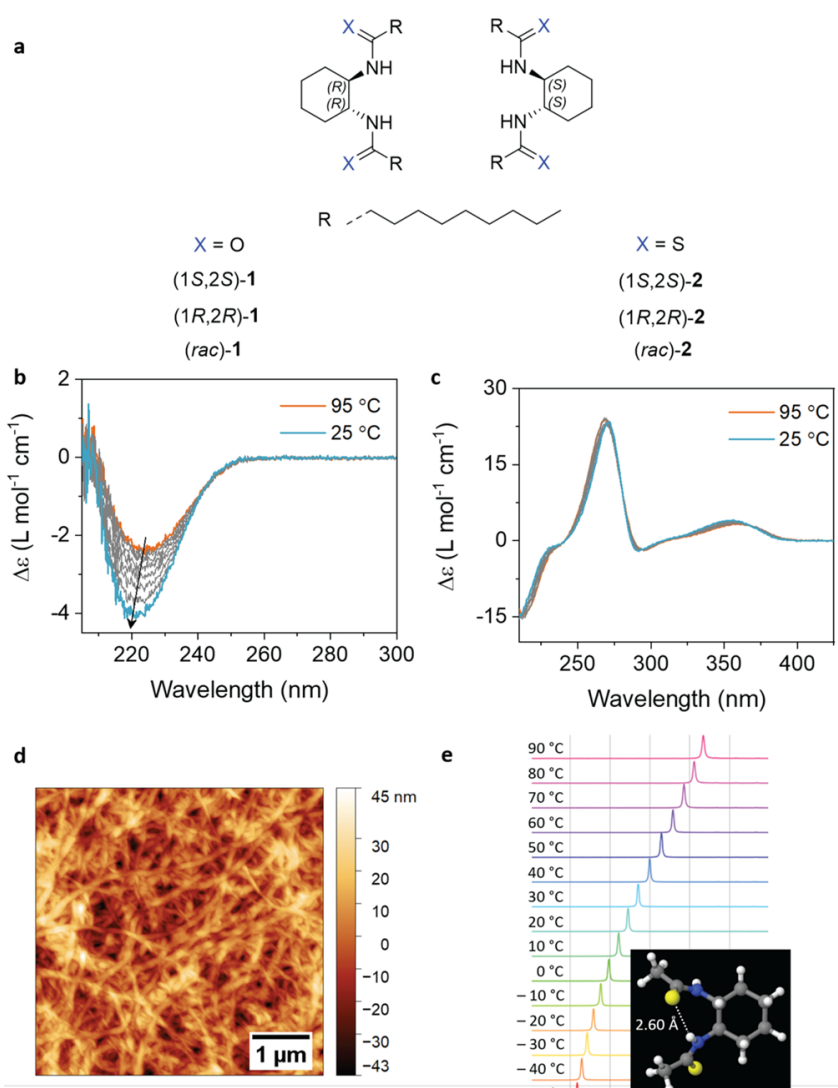

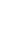
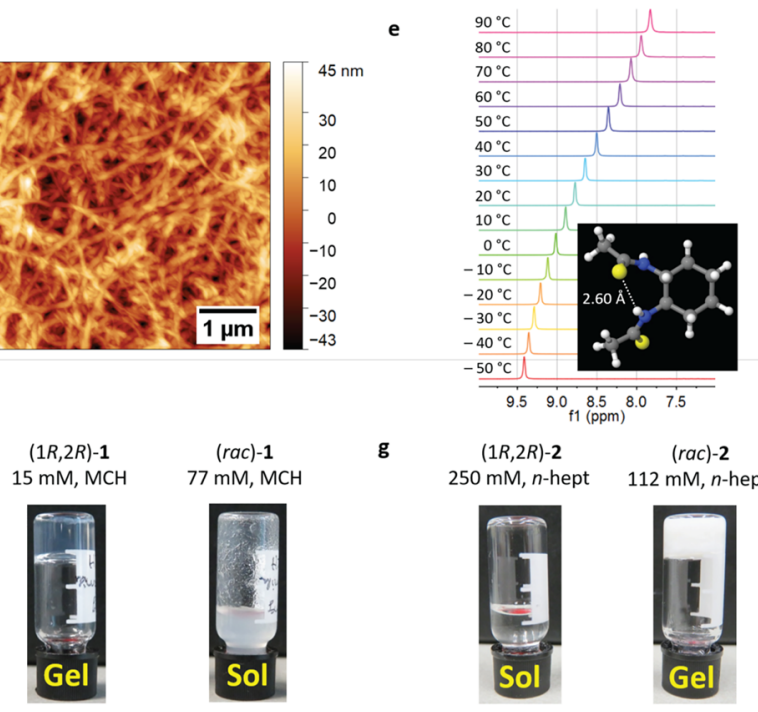

g

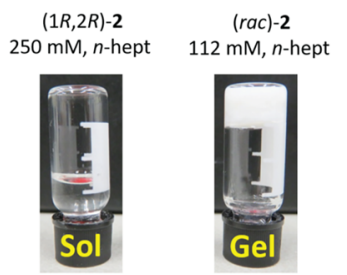

Figure 1. Comparison of assembly characteristics of trans-1,2cyclohexane carboxamide and thioamide from solution to gels. (a) Chemical structure of the carboxamides and thioamides studied. (b) Variable-temperature (VT) circular dichroism (CD) spectra of $(1 R, 2 R)-1$ in $\mathrm{MCH}(c=435 \mu \mathrm{M})$. Arrow indicates the spectral changes with decreasing temperature. (c) VT-CD spectra of $(1 R, 2 R)$ 2 in $\mathrm{MCH}(c=868 \mu \mathrm{M})$. (d) Atomic force microscopy height image of $(1 R, 2 R)-1$ on a freshly cleaved mica surface by drop-casting from a $\mathrm{MCH}$ solution $(c=383 \mu \mathrm{M})$. (e) Partial VT ${ }^{1} \mathrm{H}$ NMR spectra of $(1 R, 2 R)-2(c=18 \mathrm{mM})$ in $\mathrm{MCH}_{-} \mathrm{D}_{14}$. Only the thioamide $\mathrm{N}-\mathrm{H}$ region is shown. Inset shows the optimized geometry of a monomer (at the B3LYP/6-31+G(d,p) level of theory) with alkyl chains replaced with a methyl group. The possible intramolecular hydrogen bond is depicted in the inset. (f) Photographs of gelation tests of $(1 R, 2 R)-1$ and $(\mathrm{rac})-1$ in $\mathrm{MCH}$. At $77 \mathrm{mM}$ in $\mathrm{MCH},(\mathrm{rac})-1$ forms a weak gel, which upon gentle shaking turns into a dispersion (right photo). (g) Photographs of gelation tests of (1R,2R)-2 and ( $\mathrm{rac})-\mathbf{2}$ in $n$-heptane as the solvent. $(1 R, 2 R)-2$ dissolved readily in $n$-heptane on sonication, and no noticeable change in viscosity of the solution was observed.

network of fibers (Figure 1d). The fiber formation is mainly driven by intermolecular hydrogen bonding between monomers of $(1 R, 2 R)-1$. However, it has been previously observed for 1,2-bis(ureido)cyclohexane derivatives that different alkyl substituents on the two urea groups in the monomer result in a two-dimensional assembly rather than the thin 1-D fibers 


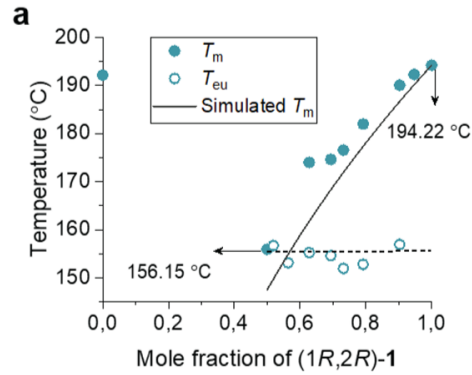

d

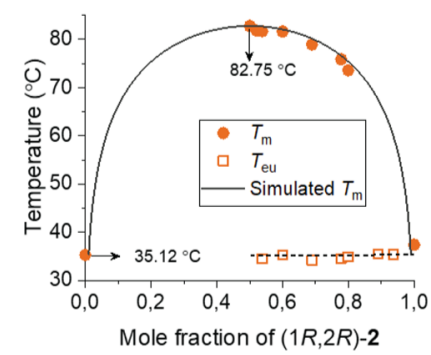

b
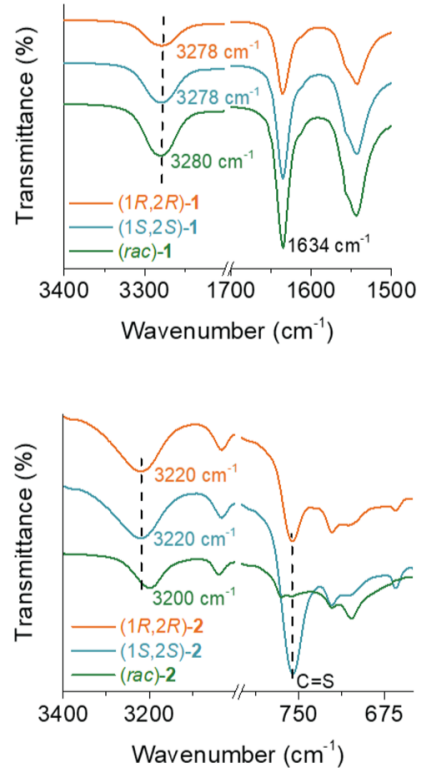

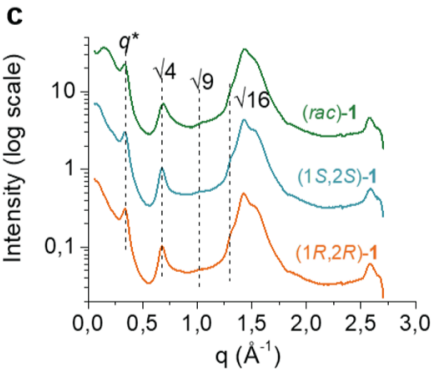

f

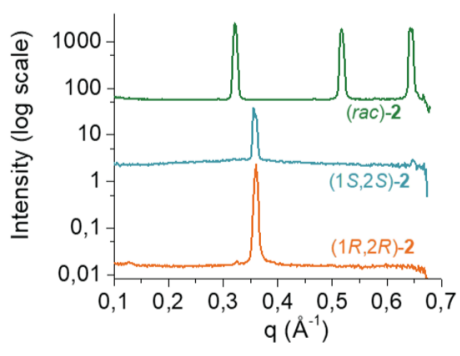

Figure 2. Comparison of solid-state assembly of 1 and 2. (a, d) Binary phase diagram of $\mathbf{1}$ and 2, respectively, obtained from differential scanning calorimetric studies. The melting temperature $\left(T_{\mathrm{m}}\right)$ and eutectic temperature $\left(T_{\text {eu }}\right)$ are determined from the second heating run at $2{ }^{\circ} \mathrm{C}$ min ${ }^{-1}$. The black solid lines in (a) and (d) represent simulated $T_{\mathrm{m}}$ curves with simplified Schröder-Van Laar and Prigogine-Defay equations, respectively (see Tables S1 and S2 for details). The dashed line indicates the variation in $T_{\text {ew }}$ and it is a guide to the eye. (b, e) Solid-state FT-IR spectra of $\mathbf{1}$ and $\mathbf{2}$, respectively. Important vibrations are marked in the graph. (c, f) Solid-state powder X-ray scattering profile of $\mathbf{1}$ and 2 , respectively. The first four major peaks in the scattering profile of 1 are marked along with their corresponding relation to the principal peak ( $q^{*}$ ). The FT-IR spectra and Xray scattering profiles are vertically shifted for clarity; thus, the transmittance and intensities are relative values.

observed for monomers containing two identical alkyl substituents on bisurea. ${ }^{50}$ We anticipate that similar van der Waals interactions between the side chains are also important to achieve long 1-D fibers observed for $(1 R, 2 R)-1$. Furthermore, at higher concentration $(15 \mathrm{mM})(1 R, 2 R)-1$ forms stable, transparent gels in $\mathrm{MCH}$. On the contrary, the racemic carboxamide $((\mathrm{rac})-\mathbf{1})$ forms only a weak gel, which turns into a suspension on gentle shaking even at much higher concentration (77 mM, Figure 1f) compared to its enantiopure counterpart. Similar VT CD and gelation characteristics have also been observed for trans-1,2-bis(amido)cyclohexane with longer alkyl chains on the carboxamide group. ${ }^{26}$ Thus, enantiomers of 1 form long, 1-D helical fibers through intermolecular hydrogen bonding assisted by the van der Waals interaction between the side chains. Enantiomers of 1 form stable gels, whereas ( $\mathrm{rac}$ )-1 forms a weaker assembly compared to its enantiopure form in apolar solvents.

On the other hand, enantiopure thioamide $(1 R, 2 R)-2$ was readily soluble in $\mathrm{MCH}$, and the $\mathrm{CD}$ spectrum at $25^{\circ} \mathrm{C}$ shows maxima in the Cotton effects at $356 \mathrm{~nm}\left(\Delta \varepsilon=+4 \mathrm{~L} \mathrm{~mol}^{-1}\right.$ $\left.\mathrm{cm}^{-1}\right)$ and $270 \mathrm{~nm}\left(\Delta \varepsilon=+23 \mathrm{~L} \mathrm{~mol}^{-1} \mathrm{~cm}^{-1}\right)$, assigned to $\mathrm{n} \rightarrow$ $\pi^{*}$ and $\pi \rightarrow \pi^{*}$ transitions of the thioamide moiety, respectively (Figure 1c). ${ }^{51}$ On increasing the temperature of the solution to $95{ }^{\circ} \mathrm{C}$, the $\mathrm{CD}$ spectrum did not decrease in intensity. Even at a concentration of $868 \mu \mathrm{M}$, only minor shifts were observed (Figure 1c). A similar observation was made at a much lower concentration of $6 \mu \mathrm{M}$ (Figure $\mathrm{S} 1$ ). The invariance of CD spectra $\left(|\Delta \varepsilon|=25 \pm 2 \mathrm{~L} \mathrm{~mol}^{-1} \mathrm{~cm}^{-1}\right.$ at 270 $\mathrm{nm})$ with variation in temperature, concentration, and solvent polarity (Figure S2) strongly suggests that the Cotton effect arises exclusively from an asymmetrically perturbed chromophore (thioamide moiety) rather than due to helical supramolecular arrangement of intermolecular hydrogen bonds between the monomers. To further verify this hypothesis, VT
${ }^{1} \mathrm{H}$ NMR studies were performed on $(1 R, 2 R)-2(c=18 \mathrm{mM})$ in $\mathrm{MCH}-\mathrm{D}_{14}$ (Figure S3). The thioamide protons remain sharp even at such high concentration, and this peak undergoes a downfield shift (from 7.83 to $9.41 \delta \mathrm{ppm}$ ) and sharpens (fwhm lowers, Figure S4) with lowering the temperature from 90 to $-50{ }^{\circ} \mathrm{C}$ (Figure 1e). These ${ }^{1} \mathrm{H}$ NMR changes clearly suggest (i) hydrogen bond formation on lowering the temperature and (ii) lack of assembly due to the sharp nature of the peak down to $-50{ }^{\circ} \mathrm{C}$.

To understand the spectroscopic changes observed in VT ${ }^{1} \mathrm{H}$ NMR, we performed quantum chemical computations on a monomer of $(1 R, 2 R)-2$ with alkyl chains replaced by methyl groups for computational tractability. The optimized structure shows close contacts $(2.60 \AA)$ between the hydrogen of $\mathrm{N}-\mathrm{H}$ on $\mathrm{C}_{1}$ of cyclohexane and sulfur of $\mathrm{C}=\mathrm{S}$ on $\mathrm{C}_{2}$ of the cyclohexane ring (inset of Figure 1e). Such $\mathrm{N}-\mathrm{H} \cdots \mathrm{S}$ distances have been ascribed to hydrogen bonding in various systems. ${ }^{52}$ Juxtaposing the downfield shift and sharpening of thioamide $\mathrm{N}-\mathrm{H}$ proton with lowering in temperature and the quantum chemical calculations, we can conclude that enantiopure thioamides (2) undergo intramolecular hydrogen bonding contrary to the intermolecular hydrogen bonding observed for carboxamides $(\mathbf{1})$ in the solution state. We further tested the gelation of thioamides in $n$-heptane as a solvent that promotes assembly through enhanced van der Waals interactions between the solute-solute and solute-solvent. Enantiopure thioamide $(1 R, 2 R)-2$ was highly soluble even at $250 \mathrm{mM}$ concentration in $n$-heptane. However, $(\mathrm{rac})-2$ forms an opaque $\mathrm{gel} /$ solid already at $112 \mathrm{mM}$ in $n$-heptane (Figure 1f). This indicates that $(\mathrm{rac})-2$ forms a stronger assembly compared to enantiopure $(1 R, 2 R)-2$. The difference in gelation ability of enantiomers and racemates of carboxamides (1) and thioamides (2) is completely contrasting, and this triggered 
our attention to further study the organization of these systems in the solid-state.

Assembly Characteristics of Carboxamides and Thioamides in the Solid-State. The assembly characteristics of carboxamides (1) and thioamides (2) in the solid-state was studied through differential scanning calorimetry (DSC), FT-IR, and X-ray scattering techniques, as a combination of these methods has been shown to be essential to ascertain the organization of enantiomeric mixtures. ${ }^{53}$ First we examined the solid-state assembly of carboxamides (1). The enantiopure carboxamides $(\mathbf{1})$ exhibit a melting temperature $\left(T_{\mathrm{m}}\right)$ around $192-195{ }^{\circ} \mathrm{C}$ (determined by DSC), whereas the ( $\left.\mathrm{rac}\right)-1$ shows a $T_{\mathrm{m}}$ at $156{ }^{\circ} \mathrm{C}$ (Figure $2 \mathrm{a}$ ). The $T_{\mathrm{m}}$ for both $(1 R, 2 R)-1$ and (rac)-1 was independent of the heating rate, and only the transition became sharper at slower heating rates (Figures S5 and S6). The enthalpies of fusion for both enantiopure $((1 R, 2 R)-1,(1 S, 2 S)-1)$ and racemic $((r a c)-1)$ carboxamides are comparable $\left(22-25 \mathrm{~kJ} \mathrm{~mol}^{-1}\right)$, indicating that the lowering in $T_{\mathrm{m}}$ for $(\mathrm{rac})-\mathbf{1}$ might be due to entropic factors caused by the packing of alkyl side chains. DSC analysis of scalemic mixtures (mixture of enantiomers in ratios other than 1:1) indicate a gradual transition of $T_{\mathrm{m}}$ from $192{ }^{\circ} \mathrm{C}$ (at 0.947 mole fraction of $(1 R, 2 R)-1)$ to $156{ }^{\circ} \mathrm{C}$ (at 0.519 mole fraction of $(1 R, 2 R)-1)$ (Figures S7 and S8, Table S1), thus reaffirming the lowering of melting point for the mixture of enantiomers. Furthermore, FT-IR spectra of enantiopure 1 show peaks at 3278 and $1634 \mathrm{~cm}^{-1}$ corresponding to hydrogen-bonded $\mathrm{N}-\mathrm{H}$ and $\mathrm{C}=\mathrm{O}$ stretching, respectively (Figure $2 \mathrm{~b}$ ). The FT-IR spectrum of (rac)-1 also shows peaks at exactly the same wavenumber as that of the enantiopure 1 (Figure 2b), suggesting that in the solid-state both enantiomers in the racemate do not interact at a molecular level. To investigate whether the mixing of individual enantiomers has any influence on their overall packing, we have studied their X-ray scattering profiles. The powder X-ray scattering profiles for both enantiopure $\mathbf{1}$ and (rac)-1 are identical (Figure 2c), and the ratio of first four peaks follows in all cases $((1 R, 2 R)-1,(1 S, 2 S)$ 1 , and $(\mathrm{rac})-1)$ a lamellar packing $\left(q^{*}, \sqrt{ } 4, \sqrt{9}\right.$, and $\sqrt{ } 16$ times $\left.q^{*}\right)$. The thickness of the lamellae obtained from X-ray studies of $1.9 \mathrm{~nm}$ matches well with the interdigitated packing of the alkyl chain of two cyclohexane moieties. The identical scattering profile for both individual enantiomers of $\mathbf{1}$ and (rac)-1 points to the fact that mixing of the enantiopure compounds does not alter their packing in the solid-state. Thus, the following observations: (i) lowering of $T_{\mathrm{m}}$ for the (rac)-1 compared to its enantiopure analogue by $\sim 37^{\circ} \mathrm{C}$, (ii) lack of interaction between the two individual enantiomers in (rac)-1, as seen by FT-IR spectroscopy, and (iii) identical packing for both individual enantiomers of 1 and ( $r a c)-1$ suggests that a mixture of enantiomers of 1 exists as individual components or, in other words, forms conglomerates or selfsort in the solid-state.

The enantiopure thioamides (2) exhibit a $T_{\mathrm{m}}$ around $\sim 35-$ $37{ }^{\circ} \mathrm{C}$, much lower (by $\sim 150{ }^{\circ} \mathrm{C}$ ) than that observed for their carboxamide counterpart. However, the racemic thioamide ((rac)-2) exhibits a $T_{\mathrm{m}}$ at $82{ }^{\circ} \mathrm{C}$ (Figure $2 \mathrm{~d}$ ), indicating that the racemate of thioamide is more stable compared to individual enantiopure compounds. For $(1 R, 2 R)-2$ and $(\mathrm{rac})$ 2 , the $T_{\mathrm{m}}$ was found to be independent of the rate of heating; only the crystallization was affected by the rate of cooling (Figures S9 and S10). Further DSC analysis of scalemic mixtures shows the gradual evolution of $T_{\mathrm{m}}$ from $37.2{ }^{\circ} \mathrm{C}$ (at 0.937 mole fraction of $(1 R, 2 R)-2)$ to $81.8^{\circ} \mathrm{C}$ (at 0.521 mole fraction of $(1 R, 2 R)-2)$ (Figures $S 11$ and S12, Table S2), confirming the increased stability for scalemic and racemic mixture of $\mathbf{2}$. To investigate whether the apparent stability of racemic thioamide is due to interaction between the individual enantiomers, FT-IR studies were carried out. The FT-IR spectra of enantiopure thioamide show a peak at $3220 \mathrm{~cm}^{-1}$, corresponding to hydrogen-bonded $\mathrm{N}-\mathrm{H}$ stretching (Figure 2e). Another prominent peak at $755 \mathrm{~cm}^{-1}$ was observed, and this arises mostly due to the $\mathrm{C}=\mathrm{S}$ stretching with contribution from coupled $\mathrm{N}-\mathrm{C}=\mathrm{S}$ stretching mode. ${ }^{54}$ The FT-IR spectrum of $(\mathrm{rac})-2$ shows the $\mathrm{N}-\mathrm{H}$ stretching at 3200 $\mathrm{cm}^{-1}$, and the $755 \mathrm{~cm}^{-1}$ mode almost vanishes. A $20 \mathrm{~cm}^{-1}$ shift of $\mathrm{N}-\mathrm{H}$ stretching to lower wavenumber for the $(\mathrm{rac})-2$ (Figure 2e) indicates a stronger hydrogen bonding for the racemate compared to its individual enantiomers. This is in agreement with the higher $T_{\mathrm{m}}$ observed for the $(\mathrm{rac})-2$ compared to its enantiopure counterpart. Furthermore, powder $\mathrm{X}$-ray scattering studies showed that both enantiopure compounds and racemate of thioamides were highly crystalline (Figure S13). Because of the highly complex powder X-ray pattern, the peaks could not be indexed to any particular crystal packing. However, it can be clearly observed that ( $\mathrm{rac}$ )2 has a completely different powder X-ray profile in the low scattering vector region compared to its enantiopure form (Figure $2 \mathrm{f}$ ), indicating that the ( $\mathrm{rac}$ )-2 has a different packing compared to enantiopure compounds.

Single-Crystal X-ray Analysis. To obtain a thorough understanding of the packing of individual enantiomers and racemate, we have performed single-crystal X-ray structure determination. The crystal structure of an enantiopure carboxamide with $n$-butyl side chains has been reported. ${ }^{27}$ Here, the carboxamides engage in intermolecular hydrogen bonding between monomers leading to a 1-D antiparallel hydrogen-bonded array. On the other hand, the unsubstituted, racemic trans-1,2-diaminocyclohexane has been observed to crystallize as conglomerates, ${ }^{55,56}$ indicating the strong propensity of these systems to form conglomerates. This is agreement with our findings that the ( $\mathrm{rac}$ )-1 exhibits self-sorting or conglomerate behavior, as noted in the previous section. However, insights into the crystal packing of thioamides are scarce, and thus we have performed single-crystal X-ray structure determination on model compounds.

We have synthesized model thioamide derivatives $((1 S, 2 S)$ tert-butylthioamide and (rac)-tert-butylthioamide, Figure 3a) comprising tert-butyl groups as substituents in place of $n$ nonane to promote the crystallization. The single-crystals of $(1 S, 2 S)$-tert-butylthioamide grown from slow evaporation of $n$ heptane with few drops of toluene crystallize in the noncentrosymmetric triclinic space group $P 1$ with four independent molecules in the unit cell (Figure $3 b$ ). Interestingly, each of the four molecules have a unique arrangement with both inter- and intramolecular hydrogen bonds involving $\mathrm{N}-\mathrm{H} \cdots \mathrm{S}$ atoms. Both inter- and intramolecular hydrogen bond distances (between the hydrogen and sulfur atoms) were in the range 2.65-2.95 $\AA$, without a clear preference for one of the two modes of hydrogen bonding. Because both the modes of hydrogen bonding are equally likely, we anticipate that in the solution phase intramolecular hydrogen bonding dominates, and only in the solid-state intermolecular hydrogen bonding and steric or van der Waals interactions of side chains become prominent. Furthermore, single-crystals of ( $\mathrm{rac}$ )-tert-butylthioamide grown from slow diffusion of $n$-pentane into toluene solution 
a
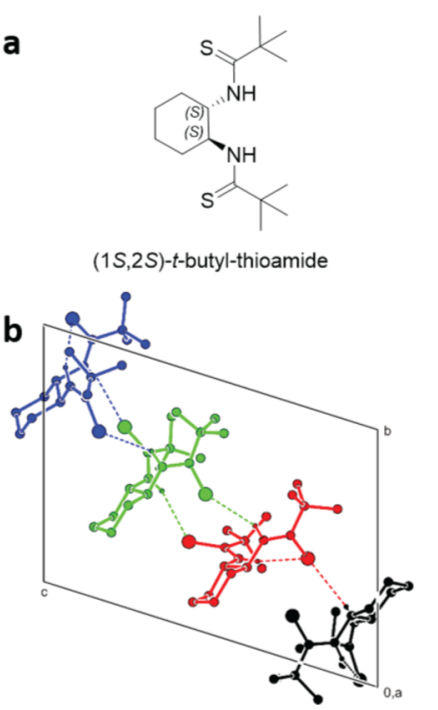

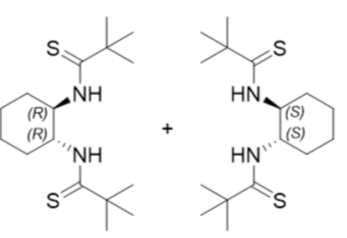

(rac)-t-butyl-thioamide

C

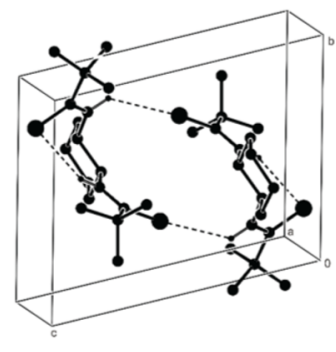

Figure 3. Crystallographic insights into the solid-state organization of thioamides. (a) Chemical structures of model thioamide derivatives studied. (b) Packing of $(1 S, 2 S)$-tert-butylthioamide in the crystal viewed along the $[1,0,0]$ direction. Symmetry-independent molecules are drawn in different colors. Only the major disorder form is shown. (c) Hydrogen-bonded dimer in the crystal structure of (rac)-tertbutylthioamide. There is only one independent molecule in the asymmetric unit. Because both the molecules in the unit cell are related by inversion symmetry, they are depicted with same color. The minor disorder form is omitted for clarity. In both (b) and (c), interand intramolecular hydrogen bonds in the unit cell are shown. The $\mathrm{C}-\mathrm{H}$ hydrogen atoms are omitted for clarity.

crystallize in the triclinic space group $P \overline{1}$ with one independent molecule in the asymmetric unit. The unit cell comprises one molecule of each individual enantiomer related by a crystallographic inversion center. They interact via both inter- and intramolecular hydrogen bonding. This unequivocally proves that in the racemate of thioamides the individual enantiomers interact with one another resulting in a coassembly, or in other words, a true racemate is formed.

Assembly of Mixed Carboxamide-Thioamide System. The contrasting assembly properties of carboxamide (1) and thioamide (2) derivatives in solution, gel, and solid-state lead us to an intriguing question: will the mixed carboxamidethioamide system (3) exhibit a mixed organization (solidsolution) due to the mutual opposing tendencies of carboxamide and thioamide in solid-state? To investigate this, we have synthesized and studied such mixed systems comprising both carboxamide and thioamide functional groups within a single enantiomer of the molecule (3, Figure 4a). The synthesis of mixed system was performed by first monoprotecting the trans-1,2-diaminocyclohexane with a tert-butyloxycarbonyl ( $t$-Boc) group and further conversion of the unprotected amine into the corresponding carboxamide using decanoyl chloride. The crucial synthetic step involved the conversion of this carboxamide into thioamide without affecting the $t$-Boc group, and this transformation was successfully achieved using Lawesson's reagent. Further the $t$ Boc group was deprotected, and the resulting amine was coupled with another equivalent of decanoyl chloride to obtain the final mixed systems (3, see Scheme S3 for details). Both the enantiopure compounds and racemate of mixed systems (3) were fully characterized by various techniques to confirm a<smiles>CCCCCCCCCCC(=O)NC1CCCCC1NC(=S)CCCCCCCC</smiles>

(1S,2S)-3 (not shown)

(1R,2R)-3 (shown)

(rac)-3

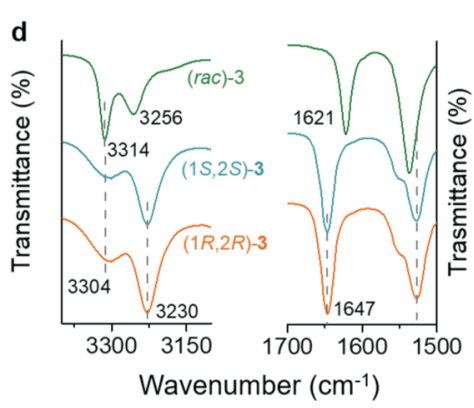

b

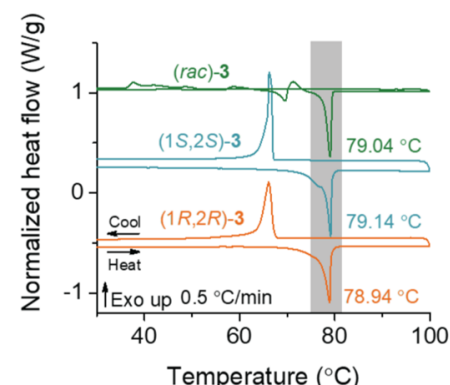

e

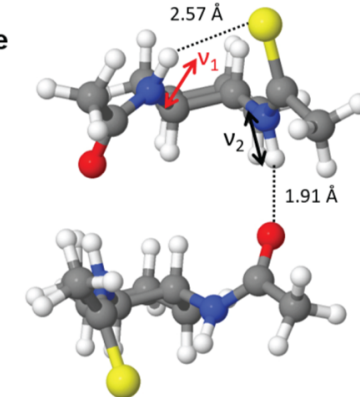

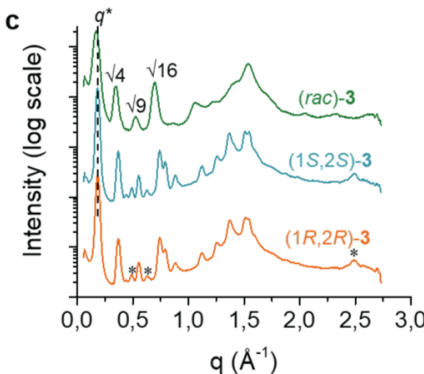

f

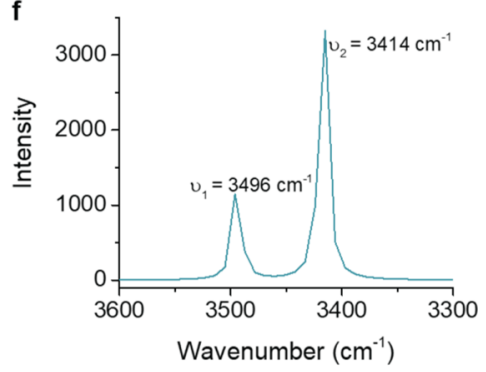

Figure 4. Solid-state assembly study of mixed carboxamide-thioamide system (3). (a) Chemical structure of mixed carboxamide-thioamide systems studied. (b) DSC thermograms of 3 with a scan rate of $0.5{ }^{\circ} \mathrm{C} \mathrm{min}{ }^{-1}$. The exact $T_{\mathrm{m}}$ for 3 is mentioned in the graph, and the gray bar represents the region of $T_{\mathrm{m}}$ for 3. (c) Solid-state powder X-ray profiles of 3 . The scattering vector ( $q$ ) relationship between the first four major peaks is shown in the graph. The peaks that are distinctly observed for $(1 S, 2 S)-3$ and $(1 R, 2 R)-3$ but become broad or masked in ( rac)-3 are marked with an asterisk. (d) Partial FT-IR spectra of 3 in the solid-state. Prominent vibrations are marked with dashed lines, and the corresponding exact values of the vibration are mentioned in the graph. (e) Optimized geometry (at the B3LYP/6-31+G(d,p) level of theory) of (1S,2S)-3 model compound (alkyl chains replaced by methyl groups). Important hydrogen-bond distances and the two kinds of $\mathrm{N}-\mathrm{H}$ stretching are marked. (f) Computed IR spectrum from the geometry obtained in (e). The fwhm of the peaks was chosen to be $4 \mathrm{~cm}^{-1}$. 
their structural integrity and purity (see the Supporting Information for synthetic details).

First, we have studied the solution-state assembly of $(1 S, 2 S)$ 3 by using circular dichroism spectroscopy. The CD spectrum of $(1 S, 2 S)-3(c=50 \mu \mathrm{M})$ in $\mathrm{MCH}$ at $95{ }^{\circ} \mathrm{C}$ shows two negative peaks at 357 and $277 \mathrm{~nm}$ corresponding to $\mathrm{n} \rightarrow \pi^{*}$ and $\pi \rightarrow \pi^{*}$ transitions, respectively. On cooling such a solution until $40{ }^{\circ} \mathrm{C}$, no change in $\mathrm{CD}$ spectra was observed. On further cooling, the Cotton effect increases in magnitude (Figure S14). These spectral changes indicate that from 95 to $40{ }^{\circ} \mathrm{C}$ the Cotton effect is mainly due to asymmetrical perturbation of chromophore, and below $40{ }^{\circ} \mathrm{C}$ the increase in magnitude of Cotton effect can be interpreted as due to assembly of monomeric units leading to helical aggregates. While the carboxamide $((1 R, 2 R)-1)$ and thioamide $((1 R, 2 R)$ 2) show monotonic changes and temperature-independent Cotton effect, respectively (Figures $1 \mathrm{~b}$ and $1 \mathrm{c}$ ), the mixed system $((1 S, 2 S)-3)$ shows a two-stage temperature-dependent $\mathrm{CD}$ change in the solution state. Furthermore, it was observed that the critical gelation concentration for both $(1 S, 2 S)-3$ and ( rac)-3 in $n$-heptane was around $275 \mathrm{mM}$ (Figure S15). This indicates that the assembly characteristics of individual enantiomers and racemate of $\mathbf{3}$ are intermediate to those of carboxamides and thioamides. With this initial indication from solution-state studies that mixed systems (3) might behave in a unique way, we have further studied their solid-state organization.

The thermal behavior of enantiopure $(1 S, 2 S)-3$ was first studied using DSC at various scan rates. At the faster scan rate of $10^{\circ} \mathrm{C} \mathrm{min}{ }^{-1}$, we observed an endothermic transition around $75^{\circ} \mathrm{C}$, just below the melting temperature of $79^{\circ} \mathrm{C}$. On slower heating/cooling at $0.5{ }^{\circ} \mathrm{C} \mathrm{min}-1$, the transition around $75{ }^{\circ} \mathrm{C}$ decreases considerably, and a sharp $T_{\mathrm{m}}$ at $79.1{ }^{\circ} \mathrm{C}\left(\Delta H_{\mathrm{f}}=\right.$ $18.78 \mathrm{~kJ} \mathrm{~mol}^{-1}$ ) was observed (Figure $\mathrm{S} 16$ ). Moreover, the crystallization temperature shifts from 62 to $66{ }^{\circ} \mathrm{C}$ on decreasing the scan rate from 10 to $0.5{ }^{\circ} \mathrm{C} \mathrm{min}^{-1}$. For $(\mathrm{rac})$ 3, a $T_{\mathrm{m}}$ at $70{ }^{\circ} \mathrm{C}$ was observed at scan rates of 10 and $20{ }^{\circ} \mathrm{C}$ $\min ^{-1}$. However, at $0.5{ }^{\circ} \mathrm{C} \min ^{-1}$, the $T_{\mathrm{m}}$ drastically shifts completely to $79{ }^{\circ} \mathrm{C}$, and moreover the crystallization temperature shifts to $40{ }^{\circ} \mathrm{C}$ and becomes broad (Figure $S 17)$. Similar DSC runs on $(1 R, 2 R)-3$ at slow scan rate showed a $T_{\mathrm{m}}$ of $78.9{ }^{\circ} \mathrm{C}$ (Figure $4 \mathrm{~b}$ ). The remarkably concurrent and single $T_{\mathrm{m}}$ of $79 \pm 0.1^{\circ} \mathrm{C}$ for both the enantiopure 3 and $(\mathrm{rac})$ 3 suggests that mixed systems might exhibit solid-solution organization. Furthermore, it is worth noting here that the $T_{\mathrm{m}}$ of enantiopure compounds of $3\left(79{ }^{\circ} \mathrm{C}\right)$ falls in between that of carboxamide $\left(1,192{ }^{\circ} \mathrm{C}\right)$ and thioamide $\left(2,37{ }^{\circ} \mathrm{C}\right)$ enantiopure compounds, indicating that the mutation at the molecular level affects the macroscopic properties in a predictable manner.

We have further looked into the FT-IR spectra of enantiopure 3 and ( $\mathrm{rac}$ )-3 to ascertain their organization. FT-IR spectra of the enantiopure 3 show two prominent peaks at 3304 and $3230 \mathrm{~cm}^{-1}$ in the $\mathrm{N}-\mathrm{H}$ stretching region (Figure $4 d)$. On the basis of quantum chemical computations of a dimer of $(1 S, 2 S)-3$ with alkyl chains replaced by methyl, we assign the peaks at 3304 and $3230 \mathrm{~cm}^{-1}$ to arise from the $\mathrm{N}-\mathrm{H}$ stretching peak of the $\mathrm{C}=\mathrm{S} \cdots \mathrm{N}-\mathrm{H}\left(\nu_{1}\right)$ and $\mathrm{C}=\mathrm{O} \cdots \mathrm{N}-\mathrm{H}$ $\left(\nu_{2}\right)$ hydrogen-bonded motifs, respectively (Figures $4 \mathrm{e}$ and $4 \mathrm{f}$ ). Also, for the enantiopure 3, the $\mathrm{C}=\mathrm{O}$ stretching is observed at $1647 \mathrm{~cm}^{-1}$, again pointing to a hydrogen-bonded carbonyl motif. For (rac)-3, both the $\mathrm{N}-\mathrm{H}$ stretching vibrations shift to higher wavenumbers $\left(3414\right.$ and $\left.3256 \mathrm{~cm}^{-1}\right)$, and the $\mathrm{C}=\mathrm{O}$ stretching shifts to $1621 \mathrm{~cm}^{-1}$. The weakening of the $\mathrm{N}-\mathrm{H}$ and strengthening of $\mathrm{C}=\mathrm{O}$ hydrogen-bonded vibrations in the (rac)-3 suggest a rearrangement in the hydrogen-bonding pattern. Furthermore, powder X-ray scattering profiles of enantiopure 3 and (rac)-3 are very comparable (Figure 4c). The small difference between the X-ray profiles of enantiopure and racemic 3 might be due to the polymorphism of the system. ${ }^{57-59}$ Detailed analysis suggests that both enantiopure 3 and ( $\mathrm{rac}$ )-3 form lamellar arrangement with $d$-spacing of 3.9 $\mathrm{nm}$. The observations such as (i) remarkably identical $T_{\mathrm{m}}$ for both enantiopure 3 and ( $r a c)-3$ and (ii) similar packing as evidenced by powder X-ray scattering profile and FT-IR spectra suggest that the mixed carboxamide-thioamide system (3) forms solid-solution with polymorphism. Because of the rather complex polymorphism and scan rate dependence of DSC profiles, here we refrain from definitely assigning the present system (3) to one of the three kinds of solid-solution possible.

\section{CONCLUSIONS}

Here we have studied the assembly processes of trans-1,2disubstituted cyclohexane systems with carboxamide (1), thioamide (2), and their combination (3) as functional groups from dilute solution to the solid-state. We have observed that both enantiopure compounds and racemate of $\mathbf{1}$ and $\mathbf{2}$ exhibit contrasting assembly in dilute solution and gelation behavior. Such an assembly behavior is also reflected in the solid-state organization, with racemates of $\mathbf{1}$ and $\mathbf{2}$ showing self-sorting or conglomerate and coassembly or true racemate, respectively (Figure 5). Detailed crystallographic studies on model

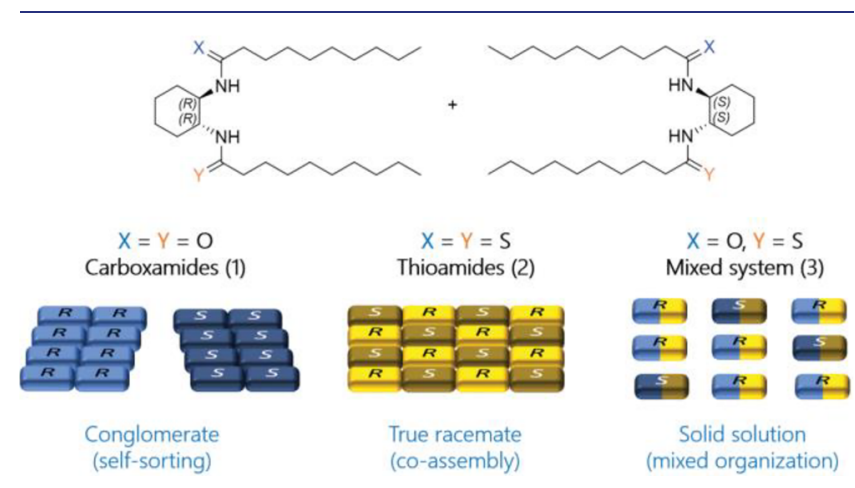

Figure 5. Schematic illustration of the solid-state assembly of the racemates of three trans-1,2-disubstituted cyclohexanes investigated in this study (1-3). For each of the systems light and dark shades are used to depict the $(1 R, 2 R)$ and $(1 S, 2 S)$ enantiomers, respectively.

compounds of 2 showed the existence of both inter- and intramolecular hydrogen bonding. The intramolecular hydrogen bonding observed for thioamides (2) is mainly responsible for their unique assembly characteristics in different phases such as solution and solid-state. The mixed carboxamidethioamide system (3) showed intermediate assembly characteristics in both the dilute solution and solid-state. Moreover, racemates of $\mathbf{3}$ form a mixed organization or solid-solution in the solid-state, mostly due to the competing assembly characteristics of carboxamide and thioamide functional units (Figure 5). Although solid-solutions of multicomponent crystals are extensively studied, ${ }^{10}$ reports on solid solutions of enantiomeric mixtures are scarce. ${ }^{11}$ Thus, we have shown a complete control over the solid-state organization of racemates by subtle structural variation of the molecular building blocks. 
We envisage that the above outlined approach of understanding the assembly of molecules in dilute solution and more concentrated gels as a guiding principle to gain control over solid-state assembly is a powerful methodology which can be applied to various systems.

\section{ASSOCIATED CONTENT}

\section{S Supporting Information}

The Supporting Information is available free of charge on the ACS Publications website at DOI: 10.1021/jacs.9b00452.

Synthetic procedures, additional DSC thermograms, and single crystal structure determination details (PDF) Crystallographic data of $(1 S, 2 S)$-tert-butylthioamide and (rac)-tert-butylthioamide (CIF)

\section{AUTHOR INFORMATION}

\section{Corresponding Authors}

*E-mail e.w.meijer@tue.nl.

*E-mail a.palmans@tue.nl.

\section{ORCID}

Chidambar Kulkarni: 0000-0001-8342-9256

José Augusto Berrocal: 0000-0003-3435-8310

Anja R. A. Palmans: 0000-0002-7201-1548

E. W. Meijer: 0000-0003-4126-7492

\section{Notes}

The authors declare no competing financial interest.

\section{ACKNOWLEDGMENTS}

We thank NWO (TOP-PUNT Grant 10018944) and the Dutch Ministry of Education, Culture, and Science (Gravitation program 024.001.035) for financial support. C.K. acknowledges Marie Skłodowska-Curie postdoctoral fellowship (704830) for financial support. We thank Dr. Bas van Genabeek and Brigitte Lamers for powder X-ray measurements. We thank OGO molecules and materials 2017-batch students for their help with synthesis in the initial phase of this work. C.K. thanks Marcin L. Slęczkowski for help with VT ${ }^{1} \mathrm{H}$ NMR measurements, Ralf Bovee for elemental analysis, and Dr. Xianwen Lou for assistance with chiral-HPLC analysis. We thank Prof. Richard M. Kellogg for fruitful discussions.

\section{REFERENCES}

(1) Pasteur, L. Recherches sur les relations qui peuvent exister entre la forme crystalline, la composition chimique et le sens de la polarisation rotatoire. Ann. Chim. Phys. 1848, 24, 442.

(2) Jacques, J.; Collet, A.; Wilen, H. S. Enantiomers, Racemates and Resolutions, 1st ed.; Krieger Publishing Company: Malabar, FL, 1991.

(3) Srisanga, S.; Ter Horst, J. H. Racemic compound, conglomerate, or solid solution: Phase diagram screening of chiral compounds. Cryst. Growth Des. 2010, 10, 1808.

(4) Wilmink, P.; Rougeot, C.; Wurst, K.; Sanselme, M.; van der Meijden, M.; Saletra, W.; Coquerel, G.; Kellogg, R. M. Attrition Induced Deracemisation of 2-Fluorophenylglycine. Org. Process Res. Dev. 2015, 19, 302.

(5) Noorduin, W. L.; Izumi, T.; Millemaggi, A.; Leeman, M.; Meekes, H.; Van Enckevort, W. J. P.; Kellogg, R. M.; Kaptein, B.; Vlieg, E.; Blackmond, D. G. Emergence of a single solid chiral state from a nearly racemic amino acid derivative. J. Am. Chem. Soc. 2008, $130,1158$.

(6) Hein, J. E.; Cao, B. H.; Viedma, C.; Kellogg, R. M.; Blackmond, D. G. Pasteur's Tweezers revisited: On the mechanism of attritionenhanced deracemization and resolution of chiral conglomerate solids. J. Am. Chem. Soc. 2012, 134, 12629.
(7) Kellogg, R.; van der Meijden, M.; Leeman, M.; Gelens, E.; Noorduin, W.; Meekes, H.; van Enckevort, W.; Kaptein, B.; Vlieg, E. Attrition-Enhanced Deracemization in the Synthesis of Clopidogrel-A Practical Application of a New Discovery. Org. Process Res. Dev. 2009, 13, 1195.

(8) Tsuji, H. Poly(lactide) stereocomplexes: Formation, structure, properties, degradation, and applications. Macromol. Biosci. 2005, 5, 569.

(9) Yang, Y.; Rice, B.; Shi, X.; Brandt, J. R.; Correa Da Costa, R.; Hedley, G. J.; Smilgies, D. M.; Frost, J. M.; Samuel, I. D. W.; OteroDe-La-Roza, A.; Johnson, E. R.; Jelfs, K. E.; Nelson, J.; Campbell, A. J.; Fuchter, M. J. Emergent Properties of an Organic Semiconductor Driven by its Molecular Chirality. ACS Nano 2017, 11, 8329.

(10) Lusi, M. Engineering Crystal Properties through Solid Solutions. Cryst. Growth Des. 2018, 18, 3704.

(11) Brandel, C.; Petit, S.; Cartigny, Y.; Coquerel, G. Structural Aspects of Solid Solutions of Enantiomers. Curr. Pharm. Des. 2016, 22, 4929.

(12) Timmermans, J. Plastic crystals: A historical review. J. Phys. Chem. Solids 1961, 18, 1.

(13) Wang, P.; Dai, Q.; Zakeeruddin, S. M.; Forsyth, M.; MacFarlane, D. R.; Grätzel, M. Ambient temperature plastic crystal electrolyte for efficient, all-solid-state dye-sensitized solar cell. J. Am. Chem. Soc. 2004, 126, 13590.

(14) Fasel, R.; Parschau, M.; Ernst, K. H. Amplification of chirality in two-dimensional enantiomorphous lattices. Nature 2006, 439, 449.

(15) Walba, D. M.; Körblova, E.; Shao, R.; Maclennan, J. E.; Link, D. R.; Glaser, M. A.; Clark, N. A. A ferroelectric liquid crystal conglomerate composed of racemic molecules. Science 2000, 288, 2181.

(16) Lin, J.; Guo, Z.; Plas, J.; Amabilino, D. B.; De Feyter, S.; Schenning, A. P. H. J. Homochiral and heterochiral assembly preferences at different length scales-conglomerates and racemates in the same assemblies. Chem. Commun. 2013, 49, 9320.

(17) Palmans, A. R. A. Deracemisations under kinetic and thermodynamic control. Mol. Syst. Des. Eng. 2017, 2, 34.

(18) Pérez-García, L.; Amabilino, D. B. Spontaneous resolution, whence and whither: From enantiomorphic solids to chiral liquid crystals, monolayers and macro- and supra-molecular polymers and assemblies. Chem. Soc. Rev. 2007, 36, 941.

(19) Lorenz, H.; Seidel-Morgenstern, A. Processes to separate enantiomers. Angew. Chem., Int. Ed. 2014, 53, 1218.

(20) Kellogg, R. M. Practical Stereochemistry. Acc. Chem. Res. 2017, 50,905 .

(21) Bennani, Y. L.; Hanessian, S. trans-1, 2-Diaminocyclohexane Derivatives as Chiral Reagents, Scaffolds, and Ligands for Catalysis: Applications in Asymmetric Synthesis and Molecular Recognition. Chem. Rev. 1997, 97, 3161.

(22) Jacobsen, E. N.; Zhang, W.; Muci, A. R.; Ecker, J. R.; Deng, L. Highly enantioselective epoxidation catalysts derived from 1, 2diaminocyclohexane. J. Am. Chem. Soc. 1991, 113, 7063.

(23) Li, M.; Li, S.-H.; Zhang, D.; Cai, M.; Duan, L.; Fung, M.-K.; Chen, C.-F. Stable Enantiomers Displaying Thermally Activated Delayed Fluorescence: Efficient OLEDs with Circularly Polarized Electroluminescence. Angew. Chem., Int. Ed. 2018, 57, 2889.

(24) Kumar, J.; Nakashima, T.; Tsumatori, H.; Mori, M.; Naito, M.; Kawai, T. Circularly polarized luminescence in supramolecular assemblies of chiral bichromophoric perylene bisimides. Chem. Eur. J. 2013, 19, 14090.

(25) Sethy, R.; Métivier, R.; Brosseau, A.; Kawai, T.; Nakashima, T. Impact of Optical Purity on the Light Harvesting Property in Supramolecular Nanofibers. J. Phys. Chem. Lett. 2018, 9, 4516.

(26) Hanabusa, K.; Yamada, M.; Kimura, M.; Shirai, H. Prominent Gelation and Chiral Aggregation of Alkylamides Derived from trans-1, 2-Diaminocyclohexane. Angew. Chem., Int. Ed. Engl. 1996, 35, 1949.

(27) Zweep, N.; Hopkinson, A.; Meetsma, A.; Browne, W. R.; Feringa, B. L.; Van Esch, J. H. Balancing hydrogen bonding and van der Waals interactions in cyclohexane-based bisamide and bisurea organogelators. Langmuir 2009, 25, 8802. 
(28) Smith, D. K. Lost in translation? Chirality effects in the selfassembly of nanostructured gel-phase materials. Chem. Soc. Rev. 2009, 38,684 .

(29) Yajima, T.; Tabuchi, E.; Nogami, E.; Yamagishi, A.; Sato, H. Perfluorinated gelators for solidifying fluorous solvents: Effects of chain length and molecular chirality. RSC Adv. 2015, 5, 80542.

(30) Sato, H.; Yajima, T.; Yamagishi, A. Stereochemical effects on dynamics in two-component systems of gelators with perfluoroalkyl and alkyl chains as revealed by vibrational circular dichroism. Phys. Chem. Chem. Phys. 2018, 20, 3210.

(31) Makiguchi, W.; Tanabe, J.; Yamada, H.; Iida, H.; Taura, D.; Ousaka, N.; Yashima, E. Chirality- and sequence-selective successive self-sorting via specific homo- and complementary-duplex formations. Nat. Commun. 2015, 6, 1.

(32) Pal, A.; Besenius, P.; Sijbesma, R. P. Self-sorting in rodlike micelles of chiral bisurea bolaamphiphiles. J. Am. Chem. Soc. 2011, 133, 12987.

(33) Narayan, B.; Bejagam, K. K.; Balasubramanian, S.; George, S. J. Autoresolution of Segregated and Mixed p-n Stacks by Stereoselective Supramolecular Polymerization in Solution. Angew. Chem., Int. Ed. 2015, 54, 13053.

(34) Sarkar, A.; Dhiman, S.; Chalishazar, A.; George, S. J. Visualization of Stereoselective Supramolecular Polymers by Chirality-Controlled Energy Transfer. Angew. Chem., Int. Ed. 2017, 56, 13767.

(35) Sethy, R.; Kumar, J.; Métivier, R.; Louis, M.; Nakatani, K.; Mecheri, N. M. T.; Subhakumari, A.; Thomas, K. G.; Kawai, T.; Nakashima, T. Enantioselective Light Harvesting with Perylenediimide Guests on Self-Assembled Chiral Naphthalenediimide Nanofibers. Angew. Chem., Int. Ed. 2017, 56, 15053.

(36) Dressel, C.; Reppe, T.; Prehm, M.; Brautzsch, M.; Tschierske, C. Chiral self-sorting and amplification in isotropic liquids of achiral molecules. Nat. Chem. 2014, 6, 971.

(37) Safont-Sempere, M. M.; Fernández, G.; Würthner, F. Selfsorting phenomena in complex supramolecular systems. Chem. Rev. 2011, 111, 5784.

(38) Ishida, Y.; Aida, T. Homochiral supramolecular polymerization of an " $\mathrm{S}$ "-shaped chiral monomer: Translation of optical purity into molecular weight distribution. J. Am. Chem. Soc. 2002, 124, 14017.

(39) Orentas, E.; Sakai, N.; Matile, S. Stereoselective Self-Sorting on Surfaces: Transcription of Chiral Information. Chirality 2013, 25, 107.

(40) Desiraju, G. R. Supramolecular Synthons in Crystal Engineering-A New Organic Synthesis. Angew. Chem., Int. Ed. Engl. 1995, 34, 2311.

(41) Von Langermann, J.; Tam, L. M.; Lorenz, H.; SeidelMorgenstern, A. Kombination von biokatalyse und kristallisation zur darstellung enantiomerenreiner mandelsäurederivate. Chem. Ing. Tech. 2010, 82, 93.

(42) Lorenz, H.; Von Langermann, J.; Sadiq, G.; Seaton, C. C.; Davey, R. J.; Seidel-Morgenstern, A. The phase behavior and crystallization of 2-chloromandelic acid: The crystal structure of the pure enantiomer and the behavior of its metastable conglomerate. Cryst. Growth Des. 2011, 11, 1549.

(43) Sigman, M. S.; Jacobsen, E. N. Schiff base catalysts for the asymmetric strecker reaction identified and optimized from parallel synthetic libraries. J. Am. Chem. Soc. 1998, 120, 4901.

(44) Yanagisawa, Y.; Nan, Y.; Okuro, K.; Aida, T. Mechanically robust, readily repairable polymers via tailored noncovalent crosslinking. Science 2018, 359, 72.

(45) Mes, T.; Cantekin, S.; Balkenende, D. W. R.; Frissen, M. M. M.; Gillissen, M. A. J.; De Waal, B. F. M.; Voets, I. K.; Meijer, E. W.; Palmans, A. R. A. Thioamides: Versatile bonds to induce directional and cooperative hydrogen bonding in supramolecular polymers. Chem. - Eur. J. 2013, 19, 8642.

(46) Newberry, R. W.; VanVeller, B.; Raines, R. T. Thioamides in the collagen triple helix. Chem. Commun. 2015, 51, 9624.

(47) Banala, S.; Süssmuth, R. D. Thioamides in nature: In search of secondary metabolites in anaerobic microorganisms. ChemBioChem 2010, 11, 1335 .
(48) Helbing, J.; Bregy, H.; Bredenbeck, J.; Pfister, R.; Hamm, P.; Huber, R.; Wachtveitl, J.; De Vico, L.; Olivucci, M. A fast photoswitch for minimally perturbed peptides: Investigation of the trans $\rightarrow$ cis photoisomerization of N-methylthioacetamide. J. Am. Chem. Soc. 2004, 126, 8823

(49) Smulders, M. M. J.; Schenning, A. P. H. J.; Meijer, E. W. Insight into the mechanisms of cooperative self-assembly: The "sergeantsand-soldiers" principle of chiral and achiral $C_{3}$-symmetrical discotic triamides. J. Am. Chem. Soc. 2008, 130, 606.

(50) van Esch, J. H.; Schoonbeek, F.; de Loos, M.; Kooijman, H.; Spek, A. L.; Kellogg, R. M.; Feringa, B. L. Cyclic Bis-Urea Compounds as Gelators for Organic Solvents. Chem. - Eur. J. 1999, 5, 937.

(51) Sandström, J.; Meriläinen, P.; Havanka, R.; Briggs, T.; Haslewood, G. A. D.; Flood, H. The Electronic Spectra of Thioamide and Thiohydrazides. Acta Chem. Scand. 1962, 16, 1616.

(52) Lee, H.-J.; Choi, Y.-S.; Lee, K.-B.; Park, J.; Yoon, C.-J. Hydrogen Bonding Abilities of Thioamides. J. Phys. Chem. A 2002, $106,7010$.

(53) Ernest, L. E.; Samuel, H. W. Stereochemistry of Organic Compounds, 1st ed.; Wiley: 1994.

(54) Suzuki, I. Infrared Spectra and Normal Vibrations of Thioamides. III. N-Methylthioformamide and N-methylthioacetamide. Bull. Chem. Soc. Jpn. 1962, 35, 1456.

(55) Cai, W.; Katrusiak, A. Enantiomeric crystallization of ( \pm )-trans1,2-diaminocyclohexane under pressure. CrystEngComm 2011, 13, 6742.

(56) Kostyanovsky, R. G.; Lakhvich, F. A.; Philipchenko, P. M.; Lenev, D. A.; Torbeev, V. Y.; Lyssenko, K. A. ( \pm )-trans-1, 2Diaminocyclohexane crystallises as a conglomerate. Mendeleev Commun. 2002, 12, 147.

(57) Rekis, T.; Berziņš, A.; Sarceviča, I.; Kons, A.; Balodis, M.; Orola, L.; Lorenz, H.; Actinš̌, A. A Maze of Solid Solutions of Pimobendan Enantiomers: An Extraordinary Case of Polymorph and Solvate Diversity. Cryst. Growth Des. 2018, 18, 264.

(58) Brandel, C.; Amharar, Y.; Rollinger, J. M.; Griesser, U. J.; Cartigny, Y.; Petit, S.; Coquerel, G. Impact of molecular flexibility on double polymorphism, solid solutions and chiral discrimination during crystallization of diprophylline enantiomers. Mol. Pharmaceutics 2013, 10, 3850.

(59) Coquerel, G. Thermodynamic predictions of physical properties - Prediction of solid solutions in molecular solutes exhibiting polymorphism. Chem. Eng. Technol. 2006, 29, 182. 